\title{
PENGARUH KONSUMSI TABLET FE DENGAN KEJADIAN KONSTIPASI PADA IBU HAMIL DI PUSKESMAS PAYUNG SEKAKI PEKANBARU
}

\author{
Susani Hayati \\ Program Studi DIII Kebidanan STIKes Payung Negeri \\ Korespondensi penulis: hayatisusani@gmail.com
}

\begin{abstract}
Abstrak
Latar belakang dan tujuan: Perubahan hormonal yang drastis pada ibu hamil dengan peningkatan progesterone menyebabkan otot-otot relaksasi, sehingga menurunkan motilitas usus yang menyebabkan konstipasi. Salah satu factor yang dapat memicu konstipasi adalah konsumsi tablet fe secara rutin pada ibu hamil membuat feses menjadi hitam, keras dan kering. Tujuan penelitian ini bermaksud untuk mengetahui pengaruh konsumsi tablet fe dengan kejadian konstipasi pada ibu hamil trimester di wilayah kerja puskesmas payung sekaki Pekanbaru.

Metode: Penelitian ini bersifat kuantitatif dengan desain penelitian analitik, menggunakan pendekatan cross sectional. Jumlah sampel pada penelitian ini adalah 65 orang. Sampel dalam penelitian ini menggunakan teknik purposive sampling dengan kriteria ibu hamil yang sudah memasuki trimeseter III. Instrumen penelitian menggunakan kuesioner, wawancara dan observasi buku KIA. Analisis univariate menghasilkan distribusi dan presentase dari tiap variabel sedangkan Analisis Bivariate untuk melihat pengaruh konsumsi tablet Fe dengan kejadian konstipasi dengan menngunakan uji statistic Chi-Square $\mathrm{p}<0,005$ dengan derajat kepercayaan $(95 \%)$.

Hasil: Hasil uji statistik Chi-square menunjukkan nilai $p$ value $0,002<0,05$ dengan CI 95\%, sehingga dapat disimpulkan bahwa terdapat hubungan yang signifikan antara kejadian konstipasi dengan konsumsi tablet $\mathrm{Fe}$. Dimana pengaruh konsumsi tablet $\mathrm{Fe}$ meningkatkan kejadian konstipasi pada ibu hamil.

Simpulan: Ibu hamil yang rutin mengkonsumsi tablet Fe lebih cenderung mengalami konstipasi Sedangkan Ibu hamil yang tidak rutin mengkonsumsi tablet $\mathrm{Fe}$ cenderung tidak mengalami konstipasi.
\end{abstract}

Kata Kunci: Ibu hamil, Konstipasi, Tablet Fe

\section{Pendahuluan}

Konstipasi merupakan suatu keadaan yang sering ditemukan di dalam masyarakat, pada umumnya dihubungkan dengan kurangnya konsumsi serat, kurang minum dan kurangnya aktifitas fisik. Pemakaian obat-obatan dan gejala depresi juga dihubungkan dengan terjadinya konstipasi. Kehamilan merupakan salah satu faktor penyebab sistemik untuk terjadinya konstipasi atau susah buang air besar.

Kehamilan adalah suatu masa yang dimulai dari konsepsi sampai lahirnya janin. Kehamilan trimester III yaitu periode 3 bulan terakhir kehamilan yang dimulai pada minggu ke-28 sampai minggu ke-40. Pada wanita hamil trimester III akan mengalami perubahan Fisiologis dan psikologis yang disebut sebagai periode penantian. Menanti kehadiran bayinya sebagai bagian dari dirinya, wanita hamil tidak sabar untuk segera melihat bayinya. Saat ini juga merupakan waktu untuk mempersiapkan kelahiran dan kedudukan sebagai orang tua seperti terpusatnya perhatian pada kelahiran bayi.

Ibu hamil harus minum satu tablet tambah darah setiap hari selama kehamilanya paling sedikit 90 tablet selama kehamilan. Akan tetapi ada beberapa efek samping dari 
mengkonsumsi tablet Fe yaitu mual, muntah, kram lambung, nyeri uluhati dan konstipasi. Efek samping yang paling sering dialami yaitu konstipasi (Yunita.2018).

Pada ibu hamil dianjurkan untuk mengkonsumsinya minimal 90 tablet selama hamil. Namun sampai saat ini belum ada kebijakan khusus dari pemerintah tentang upaya meminimalisir efek samping dari konsumsi Tablet $\mathrm{Fe}$ tersebut, khususnya mengenai konstipasi meskipun pemerintah telah mengeluarkan kebijakan tentang konsumsi Tablet $\mathrm{Fe}$ bagi ibu hamil. pada tahun 2008 bahwa dari $10 \mathrm{ibu}$ hamil terdapat 7 (70\%) yang mengalami konstipasi, sedangkan sisanya $3(30 \%)$ tidak mengalami konstipasi setelah mengkonsumsi Tablet Fe. (Nisak. 2018).

Sampai saat ini, efek samping pemakaian Tablet Fe masih menjadi masalah karena tidak semua ibu hamil mengetahui prosedur konsumsi Tablet $\mathrm{Fe}$ yang benar. wanita yang mengkonsumsi suplemen zat besi mengalami 3,5 kali lebih banyak konstipasi dibandingkan yang tidak konsumsi, sedangkan wanita yang mendapat penanganan konstipasi di masa lalu mengalami 3 kali lipat risiko konstipasi selama kehamilan. Pemeriksaan kehamilan yang diberikan kepada setiap ibu hamil perlu diupayakan agar berkualitas dan memenuhi standar pelayanan kebidanan agar aman dan efektif ( Nisak.2018).

Hubungan konstipasi dengan fe adalah bahwa dalam zat besi mengandung Cupri Sulfat dan mangan sulfat merupakan biokatalisator yang merangsang jaringan pembentukan darah dalam tubuh yang menyebabkan Peningkatan hormon progesteron yang memperlambat proses pencernaan yang membuat kondisi feses cenderung lebih keras dan lebih sulit keluar (Yunita,2018)

Hasil penelitian menunjukkan bahwa responden yang teratur mengkonsumsi tablet $\mathrm{Fe}$ sebagian besar mengalami konstipasi sebanyak 21 orang $(80,76 \%)$, responden yang tidak mengkonsumsi serat sebagian kecil mengalami konstipasi sebanyak 17 orang $(65,3 \%)$, responden yang tidak teratur mengikuti senam sebagian kecil mengalami konstipasi sebanyak 15orang (57,69\%) (Sagita. 2014).

Berdasarkan data dinas kesehatan jumlah ibu hamil di kota Pekanbaru tahun 2018 yang terbanyak adalah di Puskesmas Payung Sekaki. Jumlah ibu hamil di wilayah kerja puskesmas payung sekaki adalah 2.475 orang dan jumlah ibu hamil trimester III di wilayah kerja puskesmas Payung Sekaki adalah 187 orang. Peneliti tertarik untuk melakukan penelitian mengenai Pengaruh Konsumsi Tablet $\mathrm{Fe}$ Dengan Kejadian Konstipasi Pada Ibu Hamil Di Wilayah Kerja Puskesmas Payung Sekaki.

\section{Metode Penelitian}

Penelitian ini bersifat kuantitatif dengan desain penelitian analitik, menggunakan pendekatan cross sectional. Penelitian ini bermaksud untuk mengetahui pengaruh konsumsi tablet fe dengan kejadian konstipasi pada ibu hamil trimester di wilayah kerja puskesmas payung sekaki Pekanbaru. Jumlah sampel kasus pada penelitian ini adalah 65 orang. Sampel dalam penelitian ini menggunakan teknik purposive sampling dengan kriteria ibu hamil yang sudah memasuki trimeseter III. Populasi yang masuk sebagai sampel sebayak 65 orang ibu hamil di Wilayah Kerja Puskesmas Payung Sekaki.

Instrumen penelitian menggunakan kuesioner, wawancara dan observasi buku KIA. Analisis univariate menghasilkan distribusi dan presentase dari tiap variabel (Notoatmojo, 2002). Analisis Bivariate untuk melihat pengaruh konsumsi tablet $\mathrm{Fe}$ dengan kejadian konstipasi dengan menngunakan uji statistic Chi-Square $(\underline{\alpha 0,05})$ dengan derajat kepercayaan $\mathrm{p}<0,005$ (95\%).

\section{Hasil dan Pembahasan}

Karakteristik responden pada penelitian pengaruh konsumsi tablet fe dengan kejadian konstipasi pada ibu hamil trimester di wilayah kerja puskesmas payung sekaki Pekanbaru. adalah sebagai berikut: 
Karakteristik Responden

Tabel 1. Distribusi Frekuensi Karakteristik Responden

\begin{tabular}{|c|c|c|c|}
\hline \multirow{2}{*}{$\begin{array}{c}\text { No } \\
1\end{array}$} & \multicolumn{3}{|c|}{ Karakteristik } \\
\hline & Umur & $\mathbf{N}$ & $\%$ \\
\hline & $<20$ tahun & 6 & 9,2 \\
\hline & 20-35 tahun & 59 & 90,8 \\
\hline & $>30$ tahun & 0 & 0 \\
\hline & Total & 65 & 100 \\
\hline \multirow[t]{5}{*}{2} & Pendidikan & & \\
\hline & Dasar & 0 & 0 \\
\hline & Menengah & 61 & 93,8 \\
\hline & Tinggi & 4 & 6,2 \\
\hline & Total & 65 & 100 \\
\hline \multirow[t]{4}{*}{3} & Pekerjaan & & \\
\hline & Bekerja & 6 & 9,2 \\
\hline & Tidak bekerja & 59 & 90,8 \\
\hline & Total & 65 & 100 \\
\hline
\end{tabular}

Berdasarkan Tabel 1. dapat diketahui bahwa, mayoritas umur ibu hamil adalah 2035 tahun yaitu 59 responden (90,8\%). Mayoritas tingkat pendidikan ibu hamil adalah pendidikan menengah yaitu 61 responden (93,8\%). Mayoritas pekerjaan ibu hamil adalah tidak bekerja yaitu 59 responden $(90,8 \%)$.

Tabel 2 Distribusi Frekuensi Berdasarkan Konsumsi Tablet Fe

\begin{tabular}{cccc}
\hline & Konsumsi Tablet Fe & N & \% \\
\hline 1 & Rutin & 42 & 64,6 \\
2 & Tidak Rutin & 23 & 35,4 \\
\hline \multicolumn{2}{c}{ Total } & 65 & 100 \\
\hline
\end{tabular}

Tabel 3 Distribusi Frekuensi Berdasarkan Kejadian Konstipasi

\begin{tabular}{cccc}
\hline & Konsumsi Tablet Fe & $\mathbf{N}$ & \% \\
\hline 1 & Konstipasi & 25 & 38,5 \\
2 & Tidak Konstipasi & 40 & 61,5 \\
\hline \multicolumn{2}{c}{ Total } & 65 & 100 \\
\hline
\end{tabular}

Berdasarkan tabel 2 di atas dapat terlihat bahwa mayoritas ibu hamil rutin mengkonsumsi tablet Fe yaitu 42 responden $(64,6 \%)$. Berdasarkan tabel 3 di atas dapat terlihat bahwa mayoritas ibu hamil tidak mengalami konstipasi yaitu 40 responden $(61,5 \%)$

Tabel 4. Hasil Uji Chi Square Konsumsi Tablet Fe dengan Kejadian Konstipasi pada Ibu Hamil

\begin{tabular}{|c|c|c|c|c|c|c|c|}
\hline \multirow{3}{*}{$\begin{array}{l}\text { Konsumsi } \\
\text { Tablet Fe }\end{array}$} & \multicolumn{6}{|c|}{ Konstipasi } & \multirow{3}{*}{ P value } \\
\hline & \multicolumn{2}{|c|}{ Tidak } & \multicolumn{2}{|c|}{ Ya } & \multicolumn{2}{|c|}{ Total } & \\
\hline & $\mathbf{n}$ & $\%$ & $\mathbf{N}$ & $\%$ & n & $\%$ & \\
\hline Tidak rutin & 20 & 87,0 & 3 & 13,0 & 23 & 100 & \\
\hline Rutin & 20 & 47,6 & 22 & 52,4 & 42 & 100 & 0,002 \\
\hline Total & 40 & 61,5 & 25 & 38,5 & 65 & 100 & \\
\hline
\end{tabular}

Pada tabel 4 di atas menunjukkan bahwa tablet $\mathrm{Fe}$ lebih banyak tidak mengalami ibu hamil yang tidak rutin mengkonsumsi konstipasi yaitu sebanyak 20 orang $(87 \%)$ 
dibandingkan dengan yang mengalami konstipasi hanya 3 orang (13\%). Sedangkan ibu hamil yang rutin mengkonsumsi tablet $\mathrm{Fe}$ lebih banyak mengalami konstipasi yaitu sebanyak 22 orang $(52,4 \%)$ dibandingkan dengan ibu hamil yang tidak mengalami konstipasi yaitu 20 orang $(47,6 \%)$. Hasil uji statistik Chi-square menunjukkan nilai $p$ value $0,002<0,05$ dengan CI 95\%, sehingga dapat disimpulkan bahwa terdapat hubungan yang signifikan antara kejadian konstipasi dengan konsumsi tablet Fe. Dimana pengaruh konsumsi tablet $\mathrm{Fe}$ meningkatkan kejadian konstipasi pada ibu hamil. Kejadian konstipasi lebih cendrung pada ibu hamil yang mengkonsumsi tablet $\mathrm{Fe}$ secara rutin yaitu sebanyak 22 orang $(52,4 \%)$. Sedangkan ibu yang tidak rutin mengkonsumsi tablet $\mathrm{Fe}$ cenderung tidak mengalami konstipasi yaitu 20 orang $(87,0 \%)$.

Konsumsi Tablet Fe secara rutin akan menyebabkan warna feses menjadi kehitaman dan mengeras (Naviri, 2011). Sehingga konsumsi tablet $\mathrm{Fe}$ dapat menyebabkan konstipasi pada ibu hamil, ditambah dengan adanya relaksasi otot halus dari usus besar dikarenakan adanya peningkatan hormon progesteron, pergeseran dan penekanan terhadap perut oleh pembesaran uterus, sehingga menjadikan kerja usus menurun dan menyebabkan jarang defekasi, jumlah feses berkurang, konsistensinya keras dan kering (Piego, 2004).

Hal ini sesuai dengan hasil penelitian Yelni \& Mandasari, 2014 menunjukkan bahwa mayoritas ibu hamil yang mengalami konstipasi sebanyak 25 responden (73\%). Nilai $p$ value $0,016<0,05$, maka terdapat hubungan yang bermakna antara konsumsi tablet Fe dengan kejadian konstipasi pada ibu hamil. Begitu juga dengan penelitian Ratnawati, 2008 dengan judul hubungan konsumsi tablet $\mathrm{Fe}$ dengan kejadian konstipasi pada ibu hamil di wilayah kerja Puskesmas Hgasem Kediri, menunjukkan adanya hubungan konsumsi tablet $\mathrm{Fe}$ dengan kejadian konstipasi pada ibu hamil.

Menurut peneliti banyaknya ibu hanil yang mengalami konstipasi juga dipengaruhi oleh faktor lain seperti kurangnya asupan makanan dan sayuran yang berserat, cara mengkonsumsi tablet Fe yang kurang tepat dan kurangnya konsumsi air putih.

\section{Simpulan}

Ibu hamil yang rutin mengkonsumsi tablet $\mathrm{Fe}$ lebih cenderung mengalami konstipasi yaitu sebanyak 22 orang $(52,4 \%)$. Sedangkan Ibu hamil yang tidak rutin mengkonsumsi tablet Fe cenderung tidak mengalami konstipasi yaitu sebanyak 20 orang (87\%)

\section{Referensi}

Indrawati, P. 2010. Panduan Perawatan Kehamilan. Yogyakarta : Atma Media Press.

Is S. 2012. Jurnal Pemberian Zat Besi (Fe) Dalam Kehamilan. Madura.

Ligat, S. 2015. Jurnal Konstipasi Pada Kehamilan. Jakarta.

Naviri, dkk. 2011. Buku Pintar Ibu Hamil. Jakarta : Elex Media Komputindo

Nisak, K. 2018. Jurnal Hubungan Konstipasi dan Konsumsi Fe. Jakarta.

Notoatmodjo, S. 2012 . Metodeologi Penelitian Kesehatan. Jakarta: Rineka Cipta.

Piego, J.H.2004. Asuhan Antepartum. Jakarta : WHO

Proverawati, A. Asfuah ,S. 2009. Buku ajar Gizi Untuk Kebidanan. Yogyakarta : Nuha Medika

Saryono . 2011. Metodologi Penelitian Kesehatan. Jogyakarta : Mitra Cendekia Press.

Sagita W.L. 2014. Jurnal Gambaran Kejadian Konstipasi Dan Konsumsi Tablet Fe pada Ibu Hamil. Yogyakarta.

Shinta, W. 2017. Jurnal Upaya penanganan konstipasi pada ibu hamil trimester III. Jakarta.

Syam AF. 2008. Konstipasi pada kehamilan Penyakit-penyakit pada kehamilan peran seorang internis. Jakarta: Pusat Penerbitan Ilmu Penyakit Dalam FK UI.

Tumanggor,NA. 2014. Jurnal Fisiologi Konstipasi Ibu Hamil. Jakarta 
Yelni. A \& Mandasari.R. 2014. Jurnal Hubungan Konsumsi Tablet $\mathrm{Fe}$ Dengan Kejadian Konstipasi Pada Ibu Hamil di Jorong Sikabu, Solok dan Gantiang Di Wilayah Kerja Puskesmas Singgalang. Tanah Datar

Yunina, E. 2017. Jurnal Gambaran Kejadian Konstipasi Pada Ibu Hamil Trimester II Yang Mengkonsumsi Tablet Fe. Yogyakarta.

Wibisono, H. 2009. Solusi sehat seputar kehamilan. Jakarta : Argomedia pustaka 